\title{
Incidence, trends and histopathological pattern of cervical malignancies at BP Koirala Memorial cancer hospital, Nepal.
}

\author{
Pathak TB ${ }^{1}$, Pun $\mathrm{CB}^{1}$, Shrestha $\mathrm{S}^{1}$, Bastola $\mathrm{S}^{1}$, Bhatta $\mathrm{R}^{1}$ \\ ${ }^{l}$ Department of Pathology, BP Koirala Memorial Cancer Hospital, Bharatpur,Nepal
}

\section{Keywords: \\ Cervical malignancy; \\ Cervical screening; \\ Human papilloma virus}

\begin{abstract}
Background: Cervical cancer is one of the most common gynecological malignant tumors worldwide and the leading cause of death from genital malignancies in women. We evaluate the trends and patterns of cervical malignancies in our institution.

Materials and Methods: All the tissue slides of cervical malignancies at the department of pathology at BP Koirala Memorial cancer hospital over a period of 3 years (2009-2011) were retrieved and evaluated. Clinical data were obtained from the medical records.

Results: A total of 1955 cases were registered as gynecological malignancies, out of which cervical malignancy constitutes $1341(68 \%)$ cases followed by ovarian malignancies $425(22 \%)$ cases. Only 874 cases were included in this study due to inadequate data retrieval. The age range for cervical cancer was 24 to 92 years with a mean age of 42.5 years. Squamous cell carcinoma (92.56\%) was the most common histological type of cervical cancer, followed by adenocarcinoma (4.1\%).

Conclusion: This study has shown a high incidence of carcinoma of cervix at BP Koirala memorial cancer Hospital. Routine cytological screening of the population for cervical cancers is highly necessary as early detection of premalignant lesions.
\end{abstract}

\section{INTRODUCTION}

Cervical carcinoma is the $2^{\text {nd }}$ most common cancer in women worldwide, but the commonest in developing countries. It is said that cervical carcinoma is one of the leading cancer in women worldwide, $2^{\text {nd }}$ only to breast cancer; $80 \%$ of new cases occur in developing countries. ${ }^{1}$ In the south Asian countries, cervical carcinoma is the most frequent of gynecological malignancies. Cervical

\section{Correspondence:}

Dr. Tilak Bahadur Pathak, MD

Department of Pathology,BP Koirala Memorial Cancer Hospital

Bharatpur, Nepal.

E-mail:pathaktilak@hotmail.com screening is acknowledged as the most effective approach for cervical cancer control. However, in many countries, including most middle-income developing countries, the existing programs are failing to achieve a major impact. The pattern of gynecological malignancy is different in various geographical areas.

Cervical cancer is the most preventable cancer in women. Ironically, it is also the biggest killer amongst all cancers in Nepalese women. All women that are sexually-active are at risk of contracting it. Although there are no clear reports, it is estimated that $20 \%$ of all female cancers is linked to cervical cancer, most of those being in advanced clinical 
Table 1: Age-wise distribution of major histological types of cervical malignancy.

\begin{tabular}{|c|c|c|c|}
\hline \multirow{2}{*}{$\begin{array}{c}\text { Age } \\
\text { Group } \\
\text { Ovary }\end{array}$} & \multicolumn{2}{|c|}{ Squamous cell carcinoma } & \multirow{2}{*}{$\begin{array}{c}\text { Adenocarcinoma } \\
(\%)\end{array}$} \\
\hline & $\begin{array}{c}\text { Non keratinizing } \\
(\%)\end{array}$ & $\begin{array}{c}\text { keratinizing } \\
(\%)\end{array}$ & \\
\hline $21-30$ & $9(1.17)$ & $2(4.65 \%)$ & 0 \\
\hline $31-40$ & $102(13.31)$ & $6(13.31)$ & $5(13.88)$ \\
\hline $41-50$ & $246(32.11)$ & $9(32.11)$ & $10(27.77)$ \\
\hline $51-60$ & $204(26.63)$ & $11(26.63)$ & $13(36.11)$ \\
\hline $61-70$ & $167(21.80)$ & $12(21.80)$ & $5(13.88)$ \\
\hline$\geq 70$ & $38(4.97)$ & $3(4.96)$ & $1(2.77)$ \\
\hline Total & $766(100)$ & $43(100)$ & $36(100$ \\
\hline
\end{tabular}

Table 2: Numbers and percentage of cervical malignancies, by histopathologeal types.

\begin{tabular}{lcc}
\hline Histological type & $\begin{array}{c}\text { No. of } \\
\text { cases }\end{array}$ & \% of cases \\
\hline SCC- Large non keratinizing type & 714 & $81.69 \%$ \\
\hline SCC- keratinizing type & 43 & 4.91 \\
\hline SCC-Small non keratinizing type & 52 & 5.94 \\
\hline Adenocarcinoma & 36 & 4.11 \\
Squamous cell carcinoma in situ & 9 & 1.02 \\
SCC- microinvasive & 9 & 1.02 \\
Adenosquamous carcinoma & 7 & 0.8 \\
Adenocarcinoma in situ & 1 & 0.1 \\
Others & 3 & \\
(Rhabdomyosarcoma:1 Lymphoepithlial & & \\
carcinoma:1 & & \\
Adenoid cystic carcinoma:1) & & \\
\end{tabular}

stages. Annually, in Nepal, there are an estimated 1,100 deaths due to cervical cancer each year. ${ }^{1}$ The true incidence of cervical cancer in Nepal remains unknown because of lack of proper cancer registry system, but it remains a major challenge due to infrequent cervical Pap smear screening.

Strong risk factors for cervical cancer and its precursor have been identified and include early age of marriage, multiple sex partners, and human papilloma virus (HPV). HPV is one of the most common sexually transmitted infections in sexually active adolescent girls and young women of several economically developed countries. ${ }^{2}$ The association between certain HPV and cervical cancer is well documented and research over the past 20 years ago has revealed that the virus is etiologically related to development of most cases of cervical cancer. ${ }^{3}$ Many researches worldwide have shown that HPV is the major cause of cervical cancer in women. Specifically, about 5 types of $\operatorname{HPV}(16,18,31,32$ and 45) among the known strains have been linked to cervical cancer. According to literature, persistence infection with one of 15 high-risk HPV types is considered a necessary cause for cervical cancer. Estimates worldwide have suggested that types 16 and 18 account for $70 \%$ of all cervical cancers. In Asia, this has been liked to $67 \%$ of all cervical cancers, with Southern Asia linked to $80 \%$ of all cervical cancers. ${ }^{3}$

In Nepal, only few reports have been published on gynecological malignancy., 4 We have analyzed a larger series of cervical malignancy in 3 years period to elucidate the incidence trends and histopathological pattern of cervical malignancies.

\section{MATERIALS AND METHODS}

This is a cross-sectional descriptive study conducted at Department of pathology, BPKMCH, Bharatpur. All cases diagnosed as cervical malignancy from 2009 to 2011 were studied and classified according to WHO (2003). Squamous cell carcinoma was classified using the recommended twotiered system, keratinized and non- keratinizing (large and small cell) and assessed histologically for the degree of differentiation. Small cell category was also isolated due to its prognostic value. Patient information was obtained from clinician request forms and medical record. Exclusion criteria included inadequate information and unavailability of histopathology records (report, slides and blocks).

\section{RESULTS}

A total of 1955 cases were registered as cases of gynecological malignancy, of which cervical carcinoma constitutes $1341(68 \%)$ cases, followed by ovarian malignancies $425(22 \%)$ cases. Only 874 cases were included in this study due to lack of adequate patient information and histopathological diagnosis. The age range for cervical cancer was 24- 92 years with a mean age of 42.5 years and a peak occurrence in the $41-50$ years of age group. Squamous cell carcinoma $(92.56 \%)$ was the most common histological type of cervical cancer, followed by adenocarcinoma $(4.1 \%)$, squamous cell carcinoma in situ and early invasive carcinoma (microinvasive) 9 (1\%) cases each group. Other rare variants were also observed in 3 $(0.34 \%)$ cases which included Adenoid cystic carcinoma, lymphoepithelial carcinoma, and rhabdomyosarcoma. Among all gynecological malignancy cervical malignancies constituted $68 \%$ followed by ovarian tumors $(22 \%)$ and others (corpus, vagina, fallopian tubes; $10 \%$ ).

Cervical malignancy was seen from 24 to 92 year with a mean age of 42.5 years. More than $92 \%$ cases were within the ages 31-70 years with peak incidence at 41-50years age group constituting $31 \%$ of total cervical malignancy. The youngest patient was 24 years-old and the oldest being 92 years-old.

Regarding major cervical malignancies in different age group, non keratinizing type showed peak in earlier age than keratinizing and adenocarcinoma (Table 1). The predominant histopathological types were squamous cell 
carcinoma $(92.56 \%)$ followed by and adenocarcinoma. Among squamous cell type, majority cases were large non keratinizing type followed by small cell non-keratinizing type $(5.94 \%)$ and $(4.91 \%)$ keratinizing type (Table 2$)$.

Adenocarcinoma was higher in post menopausal women whereas SCC keratinizing type was in premenopausal women. Seventeen out of 36 cases of adenocarcinoma were diagnosed in before 40 years of age and 19 cases were diagnosed after 40 years of age. Rare variant of cervical malignancies were also observed in this series.

\section{DISCUSSION}

Global cervical cancer mortality highlights the inequities of our time- inequities in wealth, gender and access to health services. Women worldwide are exposed to HPV, yet it is primarily women in the developing world who over decades have little or no access to early screening and treatment and who die from the consequences of this virus. Today, cervical cancer is the second most common cancer among women in the developing world, and the largest cancer killer among women in most developing countries. Each year, over 500,000 women develop cervical cancer and about 275,000 women die from the disease ${ }^{6}$ By 2030 , cervical cancer is expected to kill over 474,000 women per year-over $95 \%$ of these deaths are expected to be in low and middle- income countries. $^{7}$

According to the world cancer report, cervical carcinoma is the most common carcinoma of the female genital tract in developing country and uncommon in developed counties due to the effectiveness of screening programs that assess cervical cytology by Pap smear. Pap- smear screening is designed to detect precursor lesions in cervical epithelium, which may antedate the development of invasive carcinoma by several years. In our study, not only this, but in previous analysis and other studies, cervical carcinoma is most common carcinoma among gynecological malignancies. ${ }^{4,5,7}$ This result supports published data which shows cervical cancer accounting the largest number of gynecological malignancy in women in the most developing countries. ${ }^{8}$ Cervical cancer is a major health problem, with a $75 \%$ decrease in the incidence over the past 50 years in developed countries, although it is still the second most common cause of cancer-related morbidity and mortality among women in developing countries. ${ }^{9,10}$ In our study cervical carcinoma comprises $68 \%$ of the total gynecological malignancy followed by ovarian malignancies. In an Indian study cervical carcinoma comprises $80 \%,{ }^{11}$ whereas low rates were observed in China, and Muslim countries like Pakistan and Saudi Arabia. ${ }^{1,11}$ This study showed mean age of 42.5 years and peak occurrence in the 41-50 years of age group, which is corresponding to previous study. ${ }^{7}$ Mangunkusumo et al. ${ }^{12}$ reported that uterine cervical cancer was the most frequent gynecologic malignancy $(60.3 \%)$ in Indonesian women, with genital tract neoplasm, followed by ovarian
(25.5\%) and uterine corpus carcinoma (6.9\%). Distribution of age between different types of gynecologic malignancies in our study was more or less the same as in their reports. ${ }^{12}$

The incidence of cervical cancer begins to rise at age 2029 years and increases rapidly to reach a peak usually around age 45-49year in European populations. ${ }^{13}$ The risk of developing an invasive cancer of the cervix is also higher in the age group 40-59 years in the US population. ${ }^{14}$ Mean age at diagnosis of invasive cervical cancer is 47 years in the United States. From 1995 to 1999, the US incidence of cervical cancer in girls under age 20 was 0/100,000/year; rising to $1.7 / 100,000 /$ year in women aged 20 to 24 years, and peaking at 16.5/100,000/year in women aged 45 to 49 years. Only $10 \%$ of the cases occurred in women aged 75 or more. ${ }^{15}$ Similar trend was observed in this study.

In this study, the average age of presentation of cervical cancer is 42.5 years which is earlier to previous study ${ }^{6}$ at $\mathrm{BPKMCH}$ and about one decade earlier than is seen in Nigeria and Sudan. ${ }^{16}$ The peak incidence of cervical cancer seen in age group between 41-50 in this series which is comparable to other studies. ${ }^{6,16}$ The incidence of cervical cancer begins to rise at age 20-29 years and increases rapidly to reach a peak usually around age 45-49 years in our population as well as European populations. ${ }^{17}$ The risk of developing an invasive cancer of cervix is also higher in the age group 40-59 years in our study population which is comparable to US population which is comparable to US population. ${ }^{14}$

Squamous cell carcinoma has been classified according to the degree of squamous differentiation or according to cell type into large cell keratinizing type, large cell non keratinizing type and small cell non keratinizing carcinoma. ${ }^{18}$ The basis for this distinction has been the observation that large cell keratinizing carcinoma is radioresistant relative to nonkeratinizing carcinoma, and that small cell carcinoma have worst overall prognosis.

The most common histopathological type in this study was squamous cell carcinoma non keratinizing type $(87.63 \%)$ followed by keratinizing type(4.91\%) and adenocarcinoma $(4.11 \%)$. the histopathological features of cervical carcinoma in Nepal appear to be similar to those found in US, Nigeria, Sudan, Asia, and Africa ${ }^{5,7,11,13,16,19,20}$ Adenocarcinoma and adenosquamous carcinoma represent $4.11 \%$ and $0.8 \%$ of all cervical malignancies respectively. Squamous cell carcinoma in situ and microinvasive squamous cell carcinoma represent $1.02 \%$ each. Very rare types of cervical malignancies like rhabdomyosarcoma, lymphoepithelial carcinoma, and adenoid cystic carcinoma were also observed in this series.

Adenocarcinoma is the $2^{\text {nd }}$ most common sub-type of cervical malignancy,making up about 15 to $20 \%$ of all cervical malignancies. In our study, it was second most common 
type and constituted $4.11 \%$ of cervical malignancies. This finding was corresponding to previous national $l^{4,5,7}$ and international study. ${ }^{3}$

Factors which affect prognosis include histological cell type, grading of tumor type, age of patient, and stage of disease. The clinicopathologic stage of the disease is vital in the prognostic evaluation of cervical carcinoma. It is generally appreciated that the 5-year survival is dependent on the stage of the disease. ${ }^{18}$ In our cases most of the cases were stage III. Till date we have no such study to elucidate survival of cervical carcinoma in relation to stage of disease. The late presentation of our cases have several reasons, which may be responsible for the late presentation, include patronage of trado-medicalists and spiritual healers, delayed referral from peripheral health care center, and poor educational and social status of our patients.

In Nepal, cervical cancer screening program has not been implemented by Government although it has been prioritized in its WHO support National cancer control program and the majority of women have never been screened. The

\section{REFERENCES}

1. Stewart BW, Kleihues PE. Cancers of the female reproductive tract, In: Stewart BW, Kleihues PE, eds. World Cancer Report. IARC Pres: Lyon, France; 2003.pp215-22

2. Dunne EF,Unger ER,Sternberg M,et al. Prevalence of HPV infections among females in the United States. JAMA,2007;297,813-9.

3. AI-Jashamy K, AI-Naggar RA, San P, Mashani M. Histopathological findings for cervical lesion in Malaysian women. Asian pacific Journal of cancer Prevention 2010;10:1159-62.

4. Dhakal HP, Pradhan M, Gynecological malignancy in BPKMCH, Bharatpur: Retrospective analysis of 321 cases. J Nepal Med Assoc.2001;40:108-11.

5. Dhakal HP, Pradhan M, Histological Pattern of Gynecological Cancer. J Nepal Med Assoc.2009;48:301-5.

6. Farley J, Bray J, Pisani P, Parkin DM. GLOBOCAN 2008: Cancer incidence, Mortality and prevalence Worldwide, Version 1.0 IARC Cancer Base No.10. Lyon: IARC Press, 2010.

7. Jha Ak, Jha J, Basnet B et al A scenario of Cervical Carcinoma in a cancer hospital. J Nepal med Assoc 2009; 48:199-202.

8. Ferley J, Bray J, Pisani P, Parkin DM. GLOBOCAN 2000: Cancer incidence, Mortality and Worldwide, Version 1.0 IARC Cancer Base No.5.Lyon: IARC Press,2001.

9. American College of Obstetricians and Gynecologists. ACOG practice bulletin. Diagnosis and treatment of cervical carcinomas. Number 35, May 2002. American College of Obstetricians and Gynecologists. Int J Gynaecol Obstet 2002; 78:79-91.

10. Parkin DM, Bray F, Pisani P. Global cancer statistics, CA Cancer J Clin 2005;55:74-108. authors think that lack of screening, lack of awareness and personal barriers that experience in accessing health care may attribute to the late presentation of cervical cancer case in Nepal.

\section{CONCLUSION}

This study has shown a high incidence of carcinoma of cervix at B. P. Koirala memorial cancer Hospital. Cytologybased screening program using Pap smear have been shown to be effective in early detection of cervical neoplasia. So, routine cytological screening and subsequent using an HPV DNA test of the population for cervical cancers is highly necessary. It is necessary to establish effective screening centers and educate the reproductive age group women in order to raise the level of awareness and increase the early detection of pre-invasive lesions.

\section{Acknowledgment}

We thank Ms. Jyoti Jha and Mr. Basant Ghimire for their support for data retrieval from medical record section.

11. Chhabra S, Sonak M, Prem V, Sharma S. Gynaecological malignancies in a rural institute in India. J Obstet gynaecol 2002; 426-9.

12. Mangunkusumo R, Taufik E, Setyawan S. Relative frequency of cancer in the female genital tract in Indonesia. Southeast Asian J Trop Med Public Health 1985;16:651-5.

13. Parkin DM, Bray FI, Devesa SS: Cancer burden in the year 2000. The global picture. Eur J Cancer 2001,37:4-66.

14. Jemal A, Siegel R, Ward E, Murray T,Xu J, Smigal C, Thun MJ: Cancer statistics, 2006. CA Cancer J Clin 2006, 56:106-30.

15. National cancer institute. Seer.cancer.gov/csr/1973_1999/cervix.pdf. 2000. (cited 20 January 2013). Abvailable from: http://seer.cancer. gov/csr/1973_1999/cervix.pdf.

16. Husain S, Helali T,Domi M,Bedri S. Cervical cancer in women diagnosed at the National Health laboratory, Sudan: A call for screening. Sudan JMS,Sept2011;6:183-90.

17. Parkin DM, Bray FI,Devesa SS: Cancer burden in the year 2000. The global picture.Eur J Cancer 2000, 37:S4-66.

18. Mills SE, Carter D, Greenson JK, Reuter VE, Stoler M, Sternberg's Diagnostic surgical pathology. Vol 2. Wolters Kluwer/Lippincott Williams and Wilkins, New York. 2010;2132-2179pp.

19. Shaid J, Nadira M, Sajid M, Muhammad L, Saleha M. The pattern of gynecological malignancies in 968 cases from Pakistan. Ann Saudi Med 2006;26:382-4.

20. Boo YK, Kim CW, Lee HY, Leem JH et al. Incidence Trends in Invasive Uterine Cervix cancer and carcinoma in situ in In cheon, South Korea. Asia pacific Journal of cancer Prevention 2011;12:19851988. 